\title{
Association of transient, persistent, or delayed subclinical hypocalcemia with early lactation disease, removal, and milk yield in Holstein cows
}

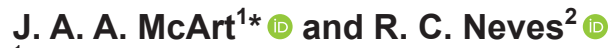 \\ ${ }^{1}$ Department of Population Medicine and Diagnostic Sciences, Cornell University, Ithaca, NY 14853 \\ ${ }^{2}$ Department of Veterinary Clinical Sciences, College of Veterinary Medicine, Purdue University, West Lafayette, IN 47907
}

\begin{abstract}
Our objectives were to evaluate the association of subclinical hypocalcemia ( $\mathrm{SCH})$ dynamics with the risk of early lactation disease, removal, and milk production. We conducted a prospective observational cohort study in 407 Holstein cows in 2 dairy herds in New York. Cows were stratified by parity group (144 primiparous, 263 multiparous) and classified into 1 of 4 groups based on postpartum plasma $\mathrm{Ca}$ concentrations previously associated with improved milk production or increased risk of disease: normocalcemic (NC; primiparous [Ca] $>2.15 \mathrm{mmol} / \mathrm{L}$ at 1 and $2 \mathrm{~d}$ in milk, $\mathrm{n}=67$; multiparous $[\mathrm{Ca}]>1.77$ at $1 \mathrm{~d}$ in milk and $2.20 \mathrm{mmol} / \mathrm{L}$ at $4 \mathrm{~d}$ in milk, $\mathrm{n}=109$ ); transient $\mathrm{SCH}$ ( $\mathrm{tSCH}$; primiparous [Ca] $\leq 2.15$ at $1 \mathrm{~d}$ in milk and $>2.15 \mathrm{mmol} / \mathrm{L}$ at $2 \mathrm{~d}$ in milk, $\mathrm{n}=25$; multiparous [Ca] $\leq 1.77$ at $1 \mathrm{~d}$ in milk and $>2.20 \mathrm{mmol} / \mathrm{L}$ at $4 \mathrm{~d}$ in milk, $\mathrm{n}=50$ ); persistent $\mathrm{SCH}$ (pSCH; primiparous [Ca] $\leq 2.15 \mathrm{mmol} / \mathrm{L}$ at 1 and $2 \mathrm{~d}$ in milk, $\mathrm{n}=33$; multiparous [Ca] $\leq 1.77$ at $1 \mathrm{~d}$ in milk and $\leq 2.20 \mathrm{mmol} / \mathrm{L}$ at $4 \mathrm{~d}$ in milk, $\mathrm{n}=34$ ); or delayed SCH (dSCH; primiparous $[\mathrm{Ca}]>2.15$ at $1 \mathrm{~d}$ in milk and $\leq 2.15 \mathrm{mmol} / \mathrm{L}$ at $2 \mathrm{~d}$ in milk, $\mathrm{n}=19$; multiparous $[\mathrm{Ca}]>1.77$ at $1 \mathrm{~d}$ in milk and $\leq 2.20 \mathrm{mmol} / \mathrm{L}$ at $4 \mathrm{~d}$ in milk, $\mathrm{n}=70$ ). Evaluated outcomes were development of an adverse event [hyperketonemia (blood $\beta$-hydroxybutyrate concentration $\geq 1.2 \mathrm{mmol} / \mathrm{L}$ at 3,5 , 7 , or $10 \mathrm{~d}$ in milk), metritis, displaced abomasum, or herd removal in the first $60 \mathrm{~d}$ in milk] and average milk yield per day across the first 10 wk of lactation. Multivariable Poisson regression was used to analyze the adverse event outcome and generalized linear mixed models for milk yield analysis. Primiparous cows with tSCH were no more likely to have an adverse event than $\mathrm{NC}$ cows $[$ risk ratio $=1.3 ; 95 \%$ confidence interval $(\mathrm{CI})$ $=0.5$ to 3.2], whereas multiparous cows tended to have a higher risk for an adverse event than $\mathrm{NC}$ cows (risk
\end{abstract}

Received June 29, 2019.

Accepted September 23, 2019.

*Corresponding author: jmcart@cornell.edu ratio $=1.4 ; 95 \% \mathrm{CI}=0.9$ to 2.1$)$. However, $\mathrm{pSCH}$ cows were 4.1 (95\% CI $=2.1$ to 7.9 , primiparous) and 1.8 ( $95 \% \mathrm{CI}=1.2$ to 2.7 , multiparous) times more likely, and $\mathrm{dSCH}$ cows 3.2 (95\% CI $=1.5$ to 7.0, primiparous) and $1.9(95 \% \mathrm{CI}=1.3$ to 2.6 , multiparous) times more likely, to have an adverse event than NC cows. Primiparous and multiparous cows with tSCH made more milk per day than $\mathrm{NC}$, pSCH, or dSCH cows across the first $10 \mathrm{wk}$ of lactation. Primiparous cows averaged $28.5 \pm$ $0.7,31.9 \pm 1.1,29.7 \pm 0.9$, and $28.7 \pm 1.2 \mathrm{~kg} / \mathrm{d}$, and multiparous cows averaged $44.6 \pm 0.7,49.1 \pm 1.1,46.4$ \pm 1.3 , and $41.4 \pm 0.9 \mathrm{~kg} / \mathrm{d}$ for $\mathrm{NC}$, tSCH, pSCH, and dSCH cows, respectively. Our results suggest that cows with tSCH adapt well to early lactation, develop fewer disease or removal events than pSCH or dSCH cows, and make more milk than $\mathrm{NC}$, pSCH, or dSCH cows. Cows with pSCH or dSCH, regardless of parity group, are at an increased risk for early lactation disease or removal events.

Key words: calcium, postpartum disease, milk yield, dairy cow

\section{INTRODUCTION}

The periparturient period requires many physiological adaptations for dairy cows as they transition from late gestation to early lactation, when homeostatic regulation of metabolic function is essential for normal parturition and lactogenesis (Bauman and Currie, 1980; Grummer, 1995; Drackley, 1999). The daily maintenance requirement of $\mathrm{Ca}$ for a nonlactating cow (the amount necessary to ensure normal bodily functions) is approximately $21 \mathrm{~g}$ (NRC, 2001). When producing $50 \mathrm{~kg}$ of milk a day, a yield often attained within $1 \mathrm{wk}$ of calving in Holsteins, a cow requires an additional 55 $\mathrm{g}$ of Ca per d (Goff, 2014); thus, her Ca requirement triples in less than $1 \mathrm{wk}$. This sudden increase in Ca demand occurs in combination with a $30 \%$ decrease in feed intake near parturition, which restricts this essential macromineral during a critical period (Hayirli et al., 2002). Appropriate homeostatic regulation of $\mathrm{Ca}$ is thus vital to ensure life and production. The inability 
to regulate blood $\mathrm{Ca}$ concentration leads to clinical hypocalcemia, which affects less than $5 \%$ of postparturient dairy cows (Goff, 2008); however, subclinical hypocalcemia (SCH), a decrease in blood Ca concentration without apparent signs of disease, affects a large proportion of our high-producing postparturient dairy cows (Reinhardt et al., 2011).

Blood Ca concentrations in "healthy" dairy cows reach a nadir at $24 \mathrm{~h}$ postpartum (Oetzel, 2004; Martinez et al., 2012). What is unclear, however, is the definition of SCH, as this varies between studies both in diagnostic threshold, ranging from 2.0 to $2.2 \mathrm{mmol} / \mathrm{L}$, as well as DIM at diagnosis, ranging from calving to 3 DIM (Martinez et al., 2012; Rodríguez et al., 2017; Venjakob et al., 2018). Thus, it is not surprising that although these studies all found a negative association of SCH on measured outcomes, these effects were not consistent between trials. One possibility for this discrepancy is that inclusion of cows in the immediate postpartum period, within $12 \mathrm{~h}$ of calving, might confound results, as recent work by Neves et al. (2018a) showed that diagnosis of $\mathrm{SCH}$ based on a single sample taken within $12 \mathrm{~h}$ of calving was a poor indicator of increased disease risk and actually associated with increased milk production in early lactation.

Results presented by Caixeta et al. (2017), and supported by Neves et al. (2018b), suggest that it is not the nadir of $\mathrm{Ca}$ concentration that increases a cow's risk of disease or reduced milk production, but rather the persistency of SCH that is associated with adverse events. Caixeta et al. (2017) showed that cows with serum total $\mathrm{Ca}$ concentration $\leq 2.15 \mathrm{mmol} / \mathrm{L}$ at 1,2 , and 3 DIM (34\% of cows in their study) have a $70 \%$ reduced odds of pregnancy to first insemination compared with normocalcemic cows. Neves et al. (2018b) showed that cows with reduced total Ca concentrations at 1 DIM had substantially greater milk yield (2.9 and $2.6 \mathrm{~kg} / \mathrm{d}$ for primiparous and multiparous cows, respectively) over the first 15 wk of lactation compared with normocalcemic cows, but that multiparous cows with reduced total $\mathrm{Ca}$ concentrations at 4 DIM had reduced milk yield $(-1.8 \mathrm{~kg} / \mathrm{d})$. Results were similar for measured disease outcomes in that cows with $\mathrm{SCH}$ at 2, 3, or 4 DIM had an increased risk of disease; the risk of subsequent disease diagnosis increased as DIM of SCH increased.

Our objective was to assess the association of early postpartum Ca status group, classified as normocalcemia (NC), transient $\mathrm{SCH}(\mathbf{t S C H})$, persistent $\mathrm{SCH}$ (pSCH), or delayed SCH (dSCH), with early lactation disease diagnosis, culling, and milk yield. A secondary objective was to assess changes in blood BHB and plasma fatty acid concentrations in the first 10 DIM between cows in different early postpartum Ca status groups. Our hypothesis was that tSCH is the physiological expression of the sudden calcium deficit and $\mathrm{pSCH}$ or $\mathrm{dSCH}$ are evidence of maladaptation of the calcium homeostatic system, such that cows with pSCH and dSCH are more likely to develop subsequent early lactation diseases, be removed from the farm, and have reduced milk yield compared with $\mathrm{NC}$ cows or cows with tSCH.

\section{MATERIALS AND METHODS}

\section{Study Population, Study Design, and Data Collection}

We conducted a prospective observational cohort study in 433 Holstein cows in 2 dairy herds in New York, as described in Neves et al. (2018b), from February to November 2015. Extensive description of the herds and rations fed in the prepartum and postpartum periods can be found in Neves et al. (2017). Of note in relation to nutritional management of hypocalcemia, herd A was fed a negative and herd B a positive prepartum DCAD diet. Herds were visited at the same time each day, and blood samples were collected 2 and 1 wk before expected calving, on the day of calving, and at 1, 2, 3, $4,5,7$, and 10 DIM from the coccygeal vessels using 20 gauge $\times 2.54 \mathrm{~cm}$ needles and $10 \mathrm{~mL}$ lithium heparin vacutainer tubes (Greiner Bio-One, Monroe, NC). Within $2 \mathrm{~h}$ of collection, we transported samples to Cornell University (Ithaca, NY), where BHB was measured in whole blood on samples from cows at 2 and $1 \mathrm{wk}$ before expected calving and at 3,5, 7, and 10 DIM using a Precision Xtra meter (Abbott Laboratories, Lake Bluff, IL; intraassay CV <3.0\%). Samples from all time points were then centrifuged at $1,000 \times g$ for $10 \mathrm{~min}$ at $22^{\circ} \mathrm{C}$ and plasma pipetted into 2 aliquots and stored at $-80^{\circ} \mathrm{C}$. One set of plasma samples was submitted to the University of Illinois Veterinary Diagnostic Laboratory (Urbana, IL) for total Ca analysis via colorimetric assay (calcium o-cresolphthalein complexone, Beckman Coulter, Brea, CA) using a high-throughput chemistry analyzer (AU680, Beckman Coulter; intra- and interassay $\mathrm{CV}<1.0 \%$ ); the remaining set of samples, including only those collected at 2, 5, and 10 DIM, was submitted to the University of Guelph Animal Health Laboratory for fatty acid analysis via colorimetric assay [HR Series NEFA-HR(2), Wake Pure Chemical Industries, Osaka, Japan] using an automated chemistry analyzer (Cobas 6000 c501, Roche Diagnostics, Indianapolis, IN; intraand interassay CV of 2.2 and $5.5 \%$, respectively).

Disease events were recorded by farm personnel into each herd's DairyComp 305 (Valley Agriculture Software, Tulare, CA) using standardized disease definitions in place before commencement of the study. Metritis was diagnosed based on physical examination 
and required the presence of a reddish to brownish uterine discharge and hyperthermia (rectal temperature $\geq 39.5^{\circ} \mathrm{C}$ ) within 14 DIM. Displaced abomasum (DA) was diagnosed based on physical examination and required the presence of the classical resonant sound of a fluid-gas interface during simultaneous auscultation and percussion in a line extending from the tuber coxae to the olecranon on the left side of the cow; this was confirmed, in all cases, by the herd's veterinarian. No right-sided DA was diagnosed for enrolled cows during the study period. Farm personnel were blinded to the purpose of the study throughout the period of data collection. Information retrieved from farm records by the research team, in addition to disease events, included calving-related information (stillbirth, twins, calving assistance), removal from the herd (sold or died), and daily milk weights. A single researcher from our group, blinded to blood metabolite and mineral data, recorded BCS and locomotion score (LS) on all cows at 3 DIM using a 5-point scale with quarter-point increments (Ferguson et al., 1994) for BCS and a 5-point scale (Sprecher et al., 1997) for LS.

All animal procedures were reviewed and approved by the participating dairies and the Cornell University Institutional Animal Care and Use Committee (protocol 2014-0171). We established the adequacy of our sample size based on analysis of our primary outcome: to determine an association of postpartum Ca status group with disease and removal in early lactation. As enrollment for this study was based from the sample size calculation of Neves et al. (2018b), inclusion of 263 multiparous cows, assuming a 25\% incidence of tSCH and $40 \%$ incidence of pSCH cows (Neves et al., 2018b), controlling for a 5\% type I error, allowed us $80 \%$ power to detect a reduction disease and removal events in early lactation (Vergara et al., 2014) from 40 to $20 \%$. Inclusion of 144 primiparous cows, assuming a $40 \%$ incidence of $\mathrm{tSCH}$ and $35 \%$ incidence of $\mathrm{pSCH}$ cows (Neves et al., 2018b), controlling for a $5 \%$ type I error, allowed us $80 \%$ power to detect a reduction in disease and removal events in early lactation (Vergara et al., 2014) from 35 to $12 \%$.

The cows and data set for this study were the same as those used in Neves et al. (2018b), with a different classification system, as described below, for determination of SCH status and outcome analysis.

\section{Exposure, Outcome, and Potential Covariate Categorization}

Cows were stratified by parity group (parity 1 , parity $\geq 2$ ) and classified into 1 of 4 postpartum $\mathrm{Ca}$ status groups based on cut-point thresholds determined by Neves et al. (2018b), wherein plasma Ca concentration was associated with positive or adverse outcomes depending on DIM and parity. Specifically, Neves et al. (2018b) found that primiparous cows with a plasma Ca concentration $\leq 2.15 \mathrm{mmol} / \mathrm{L}$ at 1 DIM produced $2.9 \mathrm{~kg}$ more milk per week than primiparous cows with a plasma Ca concentration $>2.15 \mathrm{mmol} / \mathrm{L}$; however, a plasma Ca concentration in primiparous cows $\leq 2.15 \mathrm{mmol} / \mathrm{L}$ at 2 DIM was associated with a 4.0 times greater risk of metritis, DA, or both. In multiparous cows, those with a plasma Ca concentration $\leq 1.77 \mathrm{mmol} / \mathrm{L}$ produced $2.6 \mathrm{~kg}$ more milk per week than multiparous cows with a plasma Ca concentration $>1.77 \mathrm{mmol} / \mathrm{L}$; however, a plasma Ca concentration in multiparous cows $\leq 2.20$ $\mathrm{mmol} / \mathrm{L}$ at 4 DIM was associated with production of $1.8 \mathrm{~kg}$ less milk per week than multiparous cows with a plasma Ca concentration $>2.20 \mathrm{mmol} / \mathrm{L}$. In addition, plasma Ca concentration $\leq 2.20 \mathrm{mmol} / \mathrm{L}$ for parity $\geq 3$ cows at 4 DIM was associated with a 3.1 times greater risk of subsequent diagnosis of metritis, DA, or both. Thus, our categorization into postpartum $\mathrm{Ca}$ status groups was $\mathrm{NC}$ (primiparous [Ca] $>2.15 \mathrm{mmol} / \mathrm{L}$ at 1 and 2 DIM, multiparous [Ca] $>1.77$ at 1 DIM and 2.20 $\mathrm{mmol} / \mathrm{L}$ at $4 \mathrm{DIM}$ ); tSCH (primiparous $[\mathrm{Ca}] \leq 2.15$ at $1 \mathrm{DIM}$ and $>2.15 \mathrm{mmol} / \mathrm{L}$ at $2 \mathrm{DIM}$, multiparous [Ca] $\leq 1.77$ at $1 \mathrm{DIM}$ and $>2.20 \mathrm{mmol} / \mathrm{L}$ at $4 \mathrm{DIM}$ ); $\mathrm{pSCH}$ (primiparous $[\mathrm{Ca}] \leq 2.15 \mathrm{mmol} / \mathrm{L}$ at 1 and 2 DIM, multiparous $[\mathrm{Ca}] \leq 1.77$ at $1 \mathrm{DIM}$ and $\leq 2.20 \mathrm{mmol} / \mathrm{L}$ at 4 DIM); or dSCH (primiparous [Ca] $>2.15$ at 1 DIM and $\leq 2.15 \mathrm{mmol} / \mathrm{L}$ at $2 \mathrm{DIM}$, multiparous $[\mathrm{Ca}]>1.77$ at 1 DIM and $\leq 2.20 \mathrm{mmol} / \mathrm{L}$ at $4 \mathrm{DIM})$.

Evaluated outcomes were development of a disease or herd removal within the first 60 DIM and average milk yield per day across the first $10 \mathrm{wk}$ of lactation. Disease or herd removal events included diagnosis of hyperketonemia (defined as a blood [BHB] $\geq 1.2 \mathrm{mmol} / \mathrm{L}$ at 3,5 , 7, or 10 DIM; diagnosed by the research team), metritis, DA, or removal from herd. Cows were analyzed as having a disease or removal event if they were diagnosed with one or multiple of the evaluated outcome events. As no primiparous cows were diagnosed with a DA, the disease or removal outcome for primiparous cows only included diagnosis of hyperketonemia or metritis or removal from herd or any combination of the 3 events. Daily milk yield was averaged on a weekly basis, and data from the first $10 \mathrm{wk}$ of lactation were used for analysis.

Potential covariates included calving-related variables, BCS, and LS. Cows were categorized as having a calving-related problem if they required assistance (calving ease $\geq 3$ on a 5-point scale), had a stillborn calf, or had twins. Body condition score was categorized into 3 levels: thin (BCS $\leq 2.75)$, normal $(3.0 \leq \mathrm{BCS} \leq 3.5)$, or overconditioned (BCS $\geq 3.75$ ); LS was categorized to not lame ( $\mathrm{LS} \leq 2)$ or lame ( $\mathrm{LS} \geq 3$ ). To improve 
appropriate categorization, a minimum of $10 \%$ of cows per parity group was required for each potential covariate category. Given this requirement, primiparous cows reduced to only 2 categories for BCS (normal, BCS $\leq 3.5$; overconditioned, BCS $\geq 3.75$ ), and LS did not qualify as a potential covariate for primiparous cows as only $9 \%$ had LS $\geq 3$.

\section{Statistical Analysis}

Cows were excluded from analysis due to removal from the herd before 4 DIM $(\mathrm{n}=1)$, treatment with exogenous Ca before 4 DIM $(\mathrm{n}=16)$, DA diagnosis at 0 or 1 DIM $(\mathrm{n}=1)$, lack of a 2 DIM blood sample for primiparous cows $(\mathrm{n}=2)$, or lack of a 4 DIM blood sample for multiparous cows $(\mathrm{n}=6)$. Descriptive statistics on the remaining 407 cows were performed using the FREQ procedure in SAS version 9.4 (SAS Institute Inc., Cary, NC). All explanatory models were developed using SAS and created separately for primiparous versus multiparous cows; graphs were designed via GraphPad (GraphPad Software Inc., La Jolla, CA).

BHB and Fatty Acid Concentrations. Comparison of mean BHB concentrations from approximately 2 wk prepartum to 10 DIM among Ca status groups was determined via generalized linear mixed models. Cow was nested within Ca status group to account for clustering of observations, with Ca status group as the variable of interest and DIM postpartum, parity group (parity 2, parity $\geq 3$ for the multiparous models), and herd included as potential covariates along with the interaction of parity group and Ca status group (multiparous models only). The time variable was specified in the REPEATED statement. The model was fitted using backward, stepwise elimination of potential covariates considered non-important $(P>0.10$ and $<$ $20 \%$ effect on the estimate of the variable of interest when removed). The Ca status group and herd were considered important variables a priori, and thus these variables were always maintained in the model. As time points of $\mathrm{BHB}$ concentration were not equally distributed over the period of interest, an unstructured covariance structure was chosen for the model. Normality of residuals was tested after each model fit. To achieve normality of residuals, the dependent variable (BHB) was log-transformed. Differences among least squares means between $\mathrm{Ca}$ status groups at each sample time point were adjusted for multiple comparisons using a Bonferroni correction based on 4 Ca status groups and 6 time points. Results are presented as back-transformed least squares means with $95 \%$ confidence intervals. A similar model was developed to compare mean fatty acid concentrations (2 to 10 DIM) among Ca status groups. The [fatty acid] model was log-transformed to achieve normality of residuals; differences among least squares means between Ca status groups at each sample time point were adjusted for multiple comparisons using a Bonferroni correction based on 4 Ca status groups and 3 time points.

Disease or Removal Events. Analysis of the association of Ca status group with the risk of disease or removal events was assessed using fixed-effects multivariable Poisson regression (Ospina et al., 2012). All cows were considered to have an equivalent time at risk for a disease or removal event. Potential covariates BCS, LS (multiparous only), calving-related problem, and parity group (multiparous only) were tested for univariable associations with a disease or removal outcome using Fisher's exact tests. Covariates with $P<$ 0.20 were included in each Poisson model along with the variables Ca status group and herd. The model was fit using backward stepwise elimination of potential covariates considered non-important $(P \geq 0.10$ and $<$ $20 \%$ effect on the estimate of the variable of interest when removed); Ca status group and herd were considered as important variables a priori and thus remained in both models regardless of statistical importance.

Average Daily Milk Yield. Differences in average daily milk yield among Ca status groups across the first $10 \mathrm{wk}$ of lactation were assessed using generalized linear mixed models. Approximately $2 \%$ of primiparous cow and 3\% of multiparous cow milk weights were misreported due to improper identification or loss of ear tags; these data were treated as missing values during analysis. Models were developed and fitted in the same manner as the $\mathrm{Ca}, \mathrm{BHB}$, and fatty acid models described above, with inclusion and testing of the potential covariates BCS, LS (multiparous only), calving-related problem, and parity group (multiparous only). When comparing differences among least squares means for overall and weekly milk yield between $\mathrm{Ca}$ status groups, a Bonferroni correction was used to control for multiple comparisons based on $4 \mathrm{Ca}$ status groups and 10 time points.

\section{RESULTS}

A total of 407 cows were included in the analysis; descriptive data regarding herd and parity proportions, $\mathrm{BCS}$, and the incidence of lameness, calving-related problems, and disease or removal events are in Table 1. For primiparous cows, $46.5 \%$ were NC, $17.4 \%$ tSCH, $22.9 \% \mathrm{pSCH}$, and $13.2 \% \mathrm{dSCH}$. For multiparous cows, $41.4 \%$ were $\mathrm{NC}, 19.0 \% \mathrm{tSCH}, 12.9 \% \mathrm{pSCH}$, and $26.6 \%$ $\mathrm{dSCH}$. The Ca concentration at each measured time point by Ca status group is shown in Figure 1. 


\section{Disease or Removal Events}

Descriptive data regarding the incidence of hyperketonemia, metritis, DA, and herd removal by Ca status group within parity group are in Table 2. Primiparous cows with $\mathrm{pSCH}$ or $\mathrm{dSCH}$ were 4.1 and 3.2 times more likely, respectively, to have a disease or removal event in the first 60 DIM than NC cows $(P<0.001$ and $P=$ 0.003 , respectively); no difference was observed in the risk of disease or removal events between $\mathrm{NC}$ and $\mathrm{tSCH}$ cows $(P=0.63$; Table 3$)$. No difference was observed in the risk of disease or removal events in primiparous cows between herds $(P=0.14)$.

Within multiparous cows, tSCH cows tended to have an increased risk (risk ratio $=1.4$ ) of experiencing a disease or removal event than $\mathrm{NC}$ cows $(P=0.09)$; cows with $\mathrm{pSCH}$ or $\mathrm{dSCH}$ were 1.8 and 1.9 times more likely, respectively, to have a disease or removal event in the first 60 DIM than NC cows $(P=0.006$ and $P$ $<0.001$, respectively; Table 3). Multiparous cows in herd $\mathrm{B}$ had a $30 \%$ greater risk than those in herd A of experiencing a disease or removal event.

\section{Average Daily Milk Yield}

A difference was observed in average daily milk yield of primiparous cows based on Ca status groups across the first 10 wk of lactation $(P=0.001)$ when controlling for herd $(P=0.01)$ and calving problems $(P=$ 0.02). Primiparous NC cows produced $28.5 \pm 0.7 \mathrm{~kg}$ of milk per d, whereas tSCH cows produced $31.9 \pm$ $1.1 \mathrm{~kg} / \mathrm{d}, \mathrm{pSCH}$ cows produced $29.7 \pm 0.9 \mathrm{~kg} / \mathrm{d}$, and dSCH cows produced $28.7 \pm 1.2 \mathrm{~kg} / \mathrm{d}$ (Figure 2). Milk yield of tSCH primiparous cows was greater than that of NC cows $(P=0.04)$; there were no other differences between Ca status groups.

A similarly important $(P=0.009)$ but greater difference was observed in average daily milk yield of multiparous cows across the first 10 wk of lactation based on Ca status group when controlling for herd $(P$ $=0.22$ ). Multiparous NC cows produced $44.6 \pm 0.7 \mathrm{~kg}$ milk per d, whereas tSCH cows produced $49.1 \pm 1.1$ $\mathrm{kg} / \mathrm{d}, \mathrm{pSCH}$ cows produced $46.4 \pm 1.3 \mathrm{~kg} / \mathrm{d}$, and $\mathrm{dSCH}$ cows produced $41.4 \pm 0.9 \mathrm{~kg} / \mathrm{d}$ (Figure 2). Overall, when adjusted for multiple comparisons, multiparous tSCH cows made more milk than $\mathrm{NC}$ and $\mathrm{dSCH}$ cows $(P \leq 0.001)$; no difference was observed in average daily milk production between cows in the $\mathrm{tSCH}$ and $\mathrm{pSCH}$ status groups $(P=0.12)$. Multiparous cows with dSCH had lesser daily milk yield compared with all groups 1 wk postpartum and continued to have lower milk yield compared with multiparous tSCH cows throughout the 10-wk study period. Although multiparous cows with pSCH had reduced milk yield at 1 wk postpartum compared with $\mathrm{NC}$ and $\mathrm{tSCH}$ cows, no difference was observed in wk 2 through 6 , and multiparous $\mathrm{pSCH}$ cows had greater milk yield than dSCH cows for wk 7 through 9 (Figure 2).

\section{BHB and Fatty Acid Concentrations}

A difference was observed in mean blood BHB concentration of primiparous cows over time based on $\mathrm{Ca}$ status group $(P=0.02)$ when controlling for herd $(P$ $=0.22$ ). Primiparous $\mathrm{NC}$ cows had a mean blood $\mathrm{BHB}$ concentration of $0.50 \pm 0.03 \mathrm{mmol} / \mathrm{L}$, whereas $\mathrm{tSCH}$,

Table 1. Herd and parity group proportions, BCS, and incidence of lameness, calving-related problems, and disease or removal events in the first 60 DIM in 407 Holstein cows in 2 New York dairy herds

\begin{tabular}{|c|c|c|c|c|}
\hline \multirow[b]{3}{*}{ Item } & \multicolumn{4}{|c|}{$\%$ Incidence } \\
\hline & \multicolumn{2}{|c|}{ Herd A } & \multicolumn{2}{|c|}{ Herd B } \\
\hline & $\begin{array}{l}\text { Primiparous } \\
\quad(\mathrm{n}=79)\end{array}$ & $\begin{array}{c}\text { Multiparous } \\
(\mathrm{n}=121)\end{array}$ & $\begin{array}{l}\text { Primiparous } \\
\quad(\mathrm{n}=65)\end{array}$ & $\begin{array}{c}\text { Multiparous } \\
(\mathrm{n}=142)\end{array}$ \\
\hline \multicolumn{5}{|l|}{$\mathrm{BCS}$} \\
\hline$<3.0$ & 0.0 & 20.7 & 7.7 & 6.3 \\
\hline 3.0 to 3.5 & 73.4 & 75.2 & 61.5 & 62.7 \\
\hline$>3.5$ & 26.6 & 4.1 & 30.8 & 31.0 \\
\hline Dystocia & 14.1 & 5.0 & 33.8 & 24.6 \\
\hline Stillbirth & 10.1 & 3.3 & 10.8 & 2.1 \\
\hline Twins & 0.0 & 6.6 & 1.5 & 2.1 \\
\hline Lameness $^{1}$ & 5.1 & 37.8 & 12.9 & 46.4 \\
\hline Metritis & 16.5 & 13.2 & 9.2 & 4.9 \\
\hline Hyperketonemia $^{2}$ & 21.5 & 31.4 & 16.9 & 50.0 \\
\hline Displaced abomasum & 0.0 & 5.8 & 0.0 & 4.2 \\
\hline Herd removal & 0.0 & 6.6 & 1.5 & 2.4 \\
\hline
\end{tabular}

${ }^{1}$ Lameness $=$ locomotion score $\geq 3$ on a 5 -point scale.

${ }^{2}$ Hyperketonemia $=$ blood $\mathrm{BHB} \geq 1.2 \mathrm{mmol} / \mathrm{L}$ at $3,5,7$, or $10 \mathrm{DIM}$. 
pSCH, and dSCH primiparous cows had mean blood BHB concentrations of $0.54 \pm 0.05,0.63 \pm 0.04$, and $0.54 \pm 0.06 \mathrm{mmol} / \mathrm{L}$, respectively. Differences in mean blood BHB concentration between Ca status groups were found at 3 and 5 DIM (Figure 3 ). The proportion of hyperketonemia cases at the measured DIM in primiparous cows were as follows: (3 DIM) 3.0, 4.0, 21.2 , and $5.3 \%$ of $\mathrm{NC}, \mathrm{tSCH}, \mathrm{pSCH}$, and $\mathrm{dSCH}$ cows, respectively; (5 DIM) 7.5, 12.0, 15.2, and $15.8 \%$ of $\mathrm{NC}$, tSCH, pSCH, and dSCH cows, respectively; (7 DIM) $4.5,4.0,9.1$, and $26.3 \%$ of $\mathrm{NC}, \mathrm{tSCH}, \mathrm{pSCH}$, and $\mathrm{dSCH}$ cows, respectively; and (10 DIM) 3.0, 4.0, 12.2, 10.5\% of $\mathrm{NC}, \mathrm{tSCH}, \mathrm{pSCH}$, and $\mathrm{dSCH}$ cows, respectively.

Plasma fatty acid concentration in primiparous cows also differed by $\mathrm{Ca}$ status group over time $(P=0.04)$ when controlling for herd $(P=0.01)$, with a mean plasma fatty acid concentration of $0.37 \pm 0.06,0.38$ $\pm 0.10,0.51 \pm 0.08$, and $0.43 \pm 0.11 \mathrm{mmol} / \mathrm{L}$ for $\mathrm{NC}$, tSCH, pSCH, and dSCH primiparous cows, respectively. A difference was observed in mean plasma fatty acid concentration between Ca status groups only at 2 DIM (Figure 3).
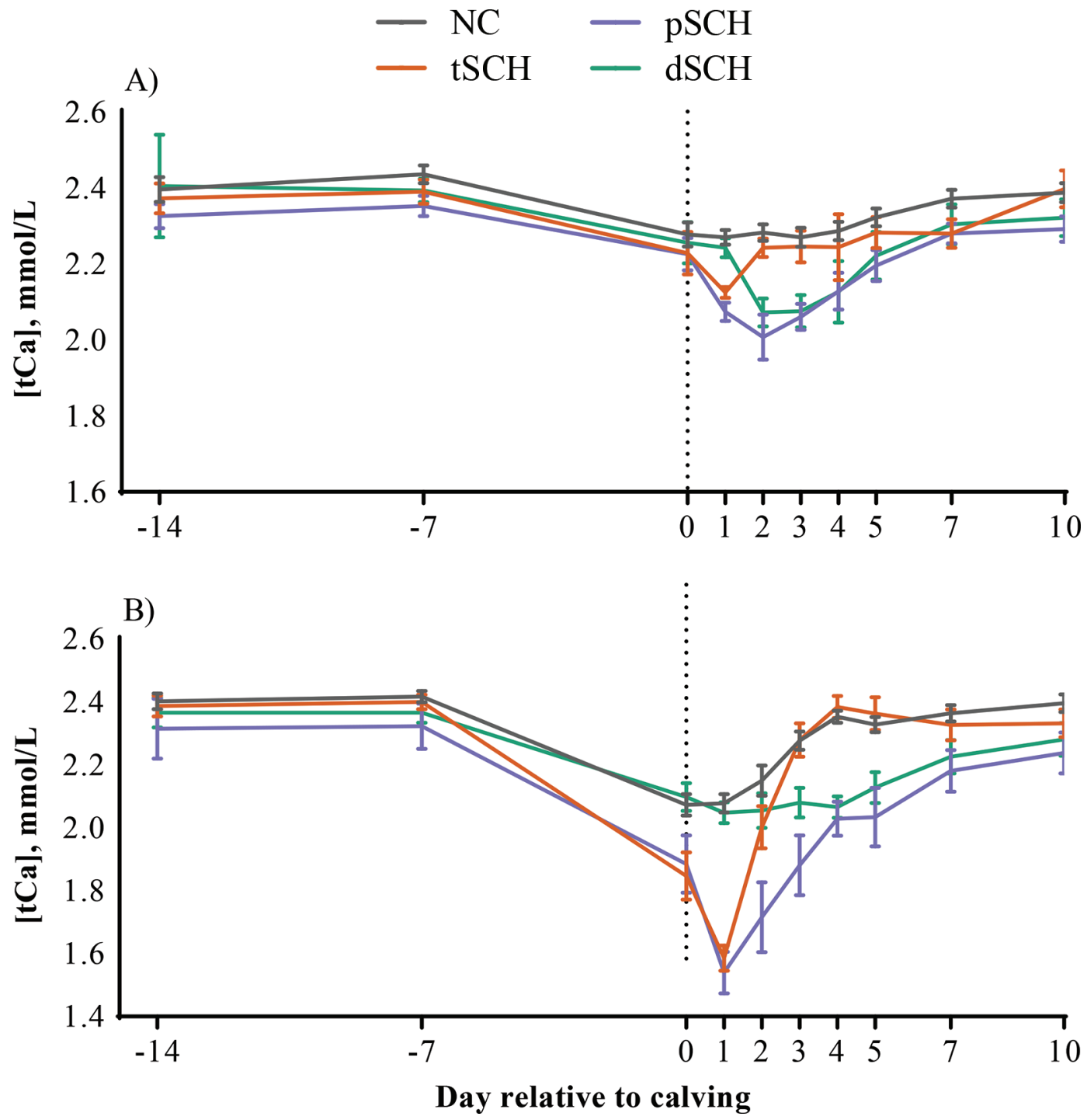

Figure 1. Mean $\pm \mathrm{SD}$ of plasma total $\mathrm{Ca}(\mathrm{tCa})$ concentration from approximately $14 \mathrm{~d}$ prepartum to $10 \mathrm{DIM}$ in $(\mathrm{A})$ primiparous $(\mathrm{n}=144)$ and $(\mathrm{B})$ multiparous $(\mathrm{n}=263)$ Holstein cows from 2 dairy herds in New York based on postpartum Ca status group. Cows were classified as follows: normocalcemic (NC, gray line; primiparous [Ca] $>2.15 \mathrm{mmol} / \mathrm{L}$ at 1 and $2 \mathrm{DIM}$, multiparous [Ca] $>1.77$ at $1 \mathrm{DIM}$ and $2.20 \mathrm{mmol} / \mathrm{L}$ at 4 DIM); transient subclinical hypocalcemia $(\mathrm{tSCH}$, orange line; primiparous $[\mathrm{Ca}] \leq 2.15$ at $1 \mathrm{DIM}$ and $>2.15 \mathrm{mmol} / \mathrm{L}$ at $2 \mathrm{DIM}$, multiparous $[\mathrm{Ca}]$ $\leq 1.77$ at $1 \mathrm{DIM}$ and $>2.20 \mathrm{mmol} / \mathrm{L}$ at $4 \mathrm{DIM}$ ); persistent subclinical hypocalcemia (pSCH, purple line; primiparous [Ca] $\leq 2.15 \mathrm{mmol} / \mathrm{L}$ at 1 and 2 DIM, multiparous $[\mathrm{Ca}] \leq 1.77$ at 1 DIM and $\leq 2.20 \mathrm{mmol} / \mathrm{L}$ at $4 \mathrm{DIM}$ ); or delayed subclinical hypocalcemia (dSCH, green line; primiparous $[\mathrm{Ca}]$ $>2.15$ at 1 DIM and $\leq 2.15 \mathrm{mmol} / \mathrm{L}$ at $2 \mathrm{DIM}$, multiparous [Ca] $>1.77$ at $1 \mathrm{DIM}$ and $\leq 2.20 \mathrm{mmol} / \mathrm{L}$ at 4 DIM). For primiparous cows, $46.5 \%$ were $\mathrm{NC}, 17.4 \% \mathrm{tSCH}, 22.9 \% \mathrm{pSCH}$, and $13.2 \%$ dSCH. For multiparous cows, $41.4 \%$ were NC, $19.0 \% \mathrm{tSCH}, 12.9 \% \mathrm{pSCH}$, and $26.6 \% \mathrm{dSCH}$. 
Table 2. Incidence of early lactation disease or removal events within the first 60 DIM in primiparous $(\mathrm{n}=144)$ and multiparous $(\mathrm{n}=263)$ Holstein cows from 2 dairy herds in New York based on postpartum Ca status group ${ }^{1}$

\begin{tabular}{|c|c|c|c|c|c|c|c|c|}
\hline \multirow{2}{*}{ Item } & \multicolumn{8}{|c|}{ Incidence, $\%$} \\
\hline & \multicolumn{4}{|c|}{ Primiparous } & \multicolumn{4}{|c|}{ Multiparous } \\
\hline Hyperketonemia $^{2}$ & 9.0 & 16.0 & 39.4 & 26.3 & 30.3 & 48.0 & 50.0 & 50.0 \\
\hline Metritis & 4.5 & 8.0 & 27.3 & 26.3 & 5.5 & 4.0 & 17.6 & 12.9 \\
\hline Adverse event ${ }^{3}$ & 14.9 & 20.0 & 57.6 & 47.4 & 33.0 & 50.0 & 61.8 & 60.0 \\
\hline
\end{tabular}

${ }^{1}$ Ca status group was categorized based on plasma $\mathrm{Ca}$ as follows: $\mathrm{NC}=$ normocalcemic (primiparous $[\mathrm{Ca}]>2.15 \mathrm{mmol} / \mathrm{L}$ at 1 and $2 \mathrm{DIM}$, multiparous $[\mathrm{Ca}]>1.77$ at $1 \mathrm{DIM}$ and $2.20 \mathrm{mmol} / \mathrm{L}$ at $4 \mathrm{DIM}) ;+\mathrm{SCH}=$ transient subclinical hypocalcemia (primiparous $[\mathrm{Ca}] \leq 2.15$ at $1 \mathrm{DIM}$ and $>2.15 \mathrm{mmol} / \mathrm{L}$ at $2 \mathrm{DIM}$, multiparous $[\mathrm{Ca}]<1.77$ at 1 DIM and $>2.20 \mathrm{mmol} / \mathrm{L}$ at $4 \mathrm{DIM}$ ); pSCH $=$ persistent subclinical hypocalcemia (primiparous $[\mathrm{Ca}] \leq 2.15 \mathrm{mmol} / \mathrm{L}$ at 1 and $2 \mathrm{DIM}$, multiparous $[\mathrm{Ca}] \leq 1.77$ at $1 \mathrm{DIM}$ and $\leq 2.20 \mathrm{mmol} / \mathrm{L}$ at 4 DIM); or dSCH $=$ delayed subclinical hypocalcemia (primiparous [Ca] $>2.15$ at $1 \mathrm{DIM}$ and $\leq 2.15 \mathrm{mmol} / \mathrm{L}$ at $2 \mathrm{DIM}$, multiparous [Ca] $>1.77$ at 1 DIM and $\leq 2.20 \mathrm{mmol} / \mathrm{L}$ at $4 \mathrm{DIM}$ ). ${ }^{2}$ Hyperketonemia diagnosed as blood BHB concentration $\geq 1.2 \mathrm{mmol} / \mathrm{L}$ at $3,5,7$, or 10 DIM.

${ }^{3}$ Adverse event $=$ one or more of hyperketonemia, metritis, displaced abomasum, or herd removal diagnoses.

A similar $(P<0.001)$ but greater difference was observed in mean blood BHB concentration of multiparous cows over time based on Ca status group when controlling for herd $(P<0.001)$. Multiparous NC cows had a mean blood BHB concentration of $0.66 \pm 0.03$ $\mathrm{mmol} / \mathrm{L}$, whereas tSCH, pSCH, and dSCH primiparous cows had mean blood BHB concentrations of $0.71 \pm$ $0.04,0.73 \pm 0.05$, and $0.72 \pm 0.03 \mathrm{mmol} / \mathrm{L}$, respectively. A difference in mean blood BHB concentration between $\mathrm{Ca}$ status groups was only found at 5 DIM (Figure 3). The proportion of hyperketonemia cases at the measured DIM in multiparous cows were as follows: (3 DIM) 7.3, 6.0, 23.5, and $24.3 \%$ of $\mathrm{NC}$, tSCH, pSCH, and dSCH cows, respectively; (5 DIM) 17.4,
$28.0,41.2,38.6 \%$ of $\mathrm{NC}, \mathrm{tSCH}, \mathrm{pSCH}$, and $\mathrm{dSCH}$ cows, respectively; (7 DIM) 19.3, 36.0, 23.5, and $28.6 \%$ of $\mathrm{NC}$, tSCH, pSCH, and dSCH cows, respectively; and (10 DIM) $18.3,32.0,20.6,15.7 \%$ of NC, tSCH, pSCH, and dSCH cows, respectively.

Plasma fatty acid concentration in multiparous cows also differed over time between Ca status groups $(P=$ $0.01)$ when controlling for herd $(P=0.42)$, with a mean plasma fatty acid concentration of $0.50 \pm 0.05,0.59$ $\pm 0.07,0.54 \pm 0.09$, and $0.57 \pm 0.06 \mathrm{mmol} / \mathrm{L}$ for $\mathrm{NC}$, tSCH, pSCH, and dSCH primiparous cows, respectively. However, no differences were observed in mean plasm fatty acid concentrations between Ca status groups on any of the DIM tested (Figure 3).

Table 3. Final Poisson regression model outcomes ${ }^{1}$ evaluating the association of postpartum Ca status group ${ }^{2}$ with occurrence of one or more disease or removal events (hyperketonemia, metritis, displaced abomasum, herd removal) within 60 DIM in 407 Holstein cows from 2 dairy herds in New York

\begin{tabular}{|c|c|c|c|c|c|c|}
\hline Calcium status group ${ }^{2}$ & $\mathrm{n}, \%$ & Estimate & SE & $P$-value & $\mathrm{RR}^{3}$ & $95 \% \mathrm{CI}$ \\
\hline Normocalcemic & $67(46.5)$ & Referent & - & - & - & - \\
\hline Transient hypocalcemia & $25(17.4)$ & 0.23 & 0.47 & 0.63 & 1.3 & 0.5 to 3.2 \\
\hline Delayed hypocalcemia & $19(13.2)$ & 1.17 & 0.40 & 0.003 & 3.2 & 1.5 to 7.0 \\
\hline \multicolumn{7}{|l|}{ Multiparous ( $\mathrm{n}=263$ ) } \\
\hline Normocalcemic & $109(41.4)$ & Referent & - & - & - & - \\
\hline Delayed hypocalcemia & $70(26.6)$ & 0.62 & 0.17 & $<0.001$ & 1.9 & 1.3 to 2.6 \\
\hline
\end{tabular}

${ }^{1}$ Primiparous model variables included Ca status group $(P<0.001)$ and herd $(P=0.14)$; multiparous model variables included Ca status group $(P=0.001)$ and herd $(P=0.08)$.

${ }^{2}$ Ca status group was categorized based on plasma Ca as follows: normocalcemic (primiparous [Ca] $>2.15$ mmol/L at 1 and 2 DIM, multiparous [Ca] $>1.77$ at 1 DIM and $2.20 \mathrm{mmol} / \mathrm{L}$ at 4 DIM); transient subclinical hypocalcemia (primiparous $[\mathrm{Ca}] \leq 2.15$ at $1 \mathrm{DIM}$ and $>2.15 \mathrm{mmol} / \mathrm{L}$ at 2 DIM, multiparous $[\mathrm{Ca}] \leq 1.77$ at 1 DIM and $>2.20 \mathrm{mmol} / \mathrm{L}$ at $4 \mathrm{DIM}$ ); persistent subclinical hypocalcemia (primiparous $[\mathrm{Ca}] \leq 2.15 \mathrm{mmol} / \mathrm{L}$ at 1 and 2 DIM, multiparous [Ca] $\leq 1.77$ at 1 DIM and $\leq 2.20 \mathrm{mmol} / \mathrm{L}$ at $4 \mathrm{DIM}$ ); or delayed subclinical hypocalcemia (primiparous [Ca] $>2.15$ at 1 DIM and $\leq 2.15 \mathrm{mmol} / \mathrm{L}$ at 2 DIM, multiparous [Ca] $>1.77$ at 1 DIM and $\leq 2.20 \mathrm{mmol} / \mathrm{L}$ at 4 DIM).

${ }^{3} \mathrm{RR}=$ relative risk. 


\section{DISCUSSION}

Our study describes different classifications of early postpartum Ca status groups and shows associations between these Ca status groups and the risk of early lactation disease or removal events and milk yield. Overall, for both primiparous and multiparous parity groups, we found little to no negative associations of tSCH with early lactation disease or herd removal, and cows with tSCH made substantially more milk in the first 10 wk of lactation than NC cows. Conversely, cows with $\mathrm{pSCH}$ or $\mathrm{dSCH}$ had a much greater risk of early lactation disease or herd removal than $\mathrm{NC}$ cows, and milk yield, depending on parity group, was either no better or numerically worse than that of NC cows.
Interestingly, the proportions of cows in each of the $4 \mathrm{Ca}$ status group classifications varied between parity groups. For both primiparous and multiparous cows in our study, the majority (approximately 40 to $45 \%$ ) were $\mathrm{NC}$, and the prevalence of $\mathrm{tSCH}$ cows was also similar, representing just under $20 \%$ of the population in both parity groups. Whereas the prevalence of pSCH was high in primiparous cows at $22.9 \%$, it was the least prevalent $\mathrm{Ca}$ status group in multiparous cows at $12.9 \%$. Conversely, dSCH was uncommon in primiparous cows with a prevalence of $13.2 \%$, yet just over $25 \%$ of multiparous cows had dSCH. To our knowledge, no studies have reported on the prevalence of different classifications of postpartum hypocalcemia when classification has been based on parity, varying
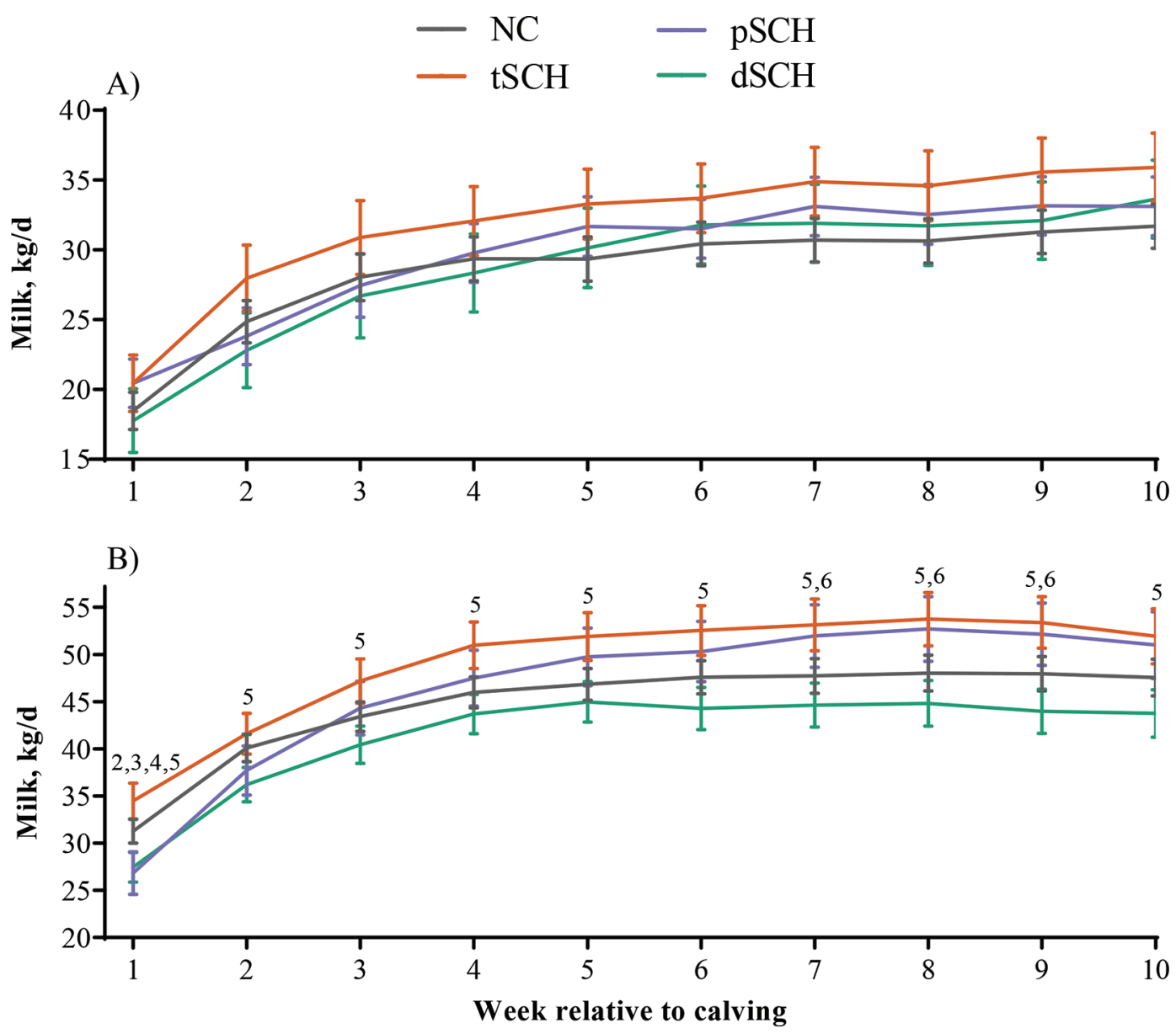

Figure 2. Least squares means and $95 \%$ CI of average daily milk yield by week across the first 10 wk of lactation in $(\mathrm{A})$ primiparous $(\mathrm{n}=$ 144) and $(B)$ multiparous $(n=263)$ Holstein cows from 2 dairy herds in New York based on postpartum Ca status group. Cows were classified as follows: normocalcemic (NC, gray line; primiparous [Ca] $>2.15 \mathrm{mmol} / \mathrm{L}$ at 1 and $2 \mathrm{DIM}$, multiparous [Ca] $>1.77$ at $1 \mathrm{DIM}$ and $2.20 \mathrm{mmol} / \mathrm{L}$ at 4 DIM); transient subclinical hypocalcemia (tSCH, orange line; primiparous [Ca] $\leq 2.15$ at 1 DIM and $>2.15 \mathrm{mmol} / \mathrm{L}$ at 2 DIM, multiparous $[\mathrm{Ca}] \leq 1.77$ at $1 \mathrm{DIM}$ and $>2.20 \mathrm{mmol} / \mathrm{L}$ at $4 \mathrm{DIM})$; persistent subclinical hypocalcemia (pSCH, purple line; primiparous [Ca] $\leq 2.15 \mathrm{mmol} / \mathrm{L}$ at 1 and 2 DIM, multiparous [Ca] $\leq 1.77$ at 1 DIM and $\leq 2.20 \mathrm{mmol} / \mathrm{L}$ at $4 \mathrm{DIM}$ ); or delayed subclinical hypocalcemia (dSCH, green line; primiparous $[\mathrm{Ca}]>2.15$ at $1 \mathrm{DIM}$ and $<2.15 \mathrm{mmol} / \mathrm{L}$ at $2 \mathrm{DIM}$, multiparous $[\mathrm{Ca}]>1.77$ at $1 \mathrm{DIM}$ and $<2.20 \mathrm{mmol} / \mathrm{L}$ at 4 DIM). Differences in average daily milk yield among Ca status groups within a time point, based on a Bonferroni corrected $P<0.05$, are represented with numerals as follows: 1 $=\mathrm{NC}$ vs. $\mathrm{tSCH}, 2=\mathrm{NC}$ vs. pSCH, $3=\mathrm{NC}$ vs. dSCH, $4=\mathrm{tSCH}$ vs. pSCH, $5=\mathrm{tSCH}$ vs. dSCH, $6=\mathrm{pSCH}$ vs. dSCH. 

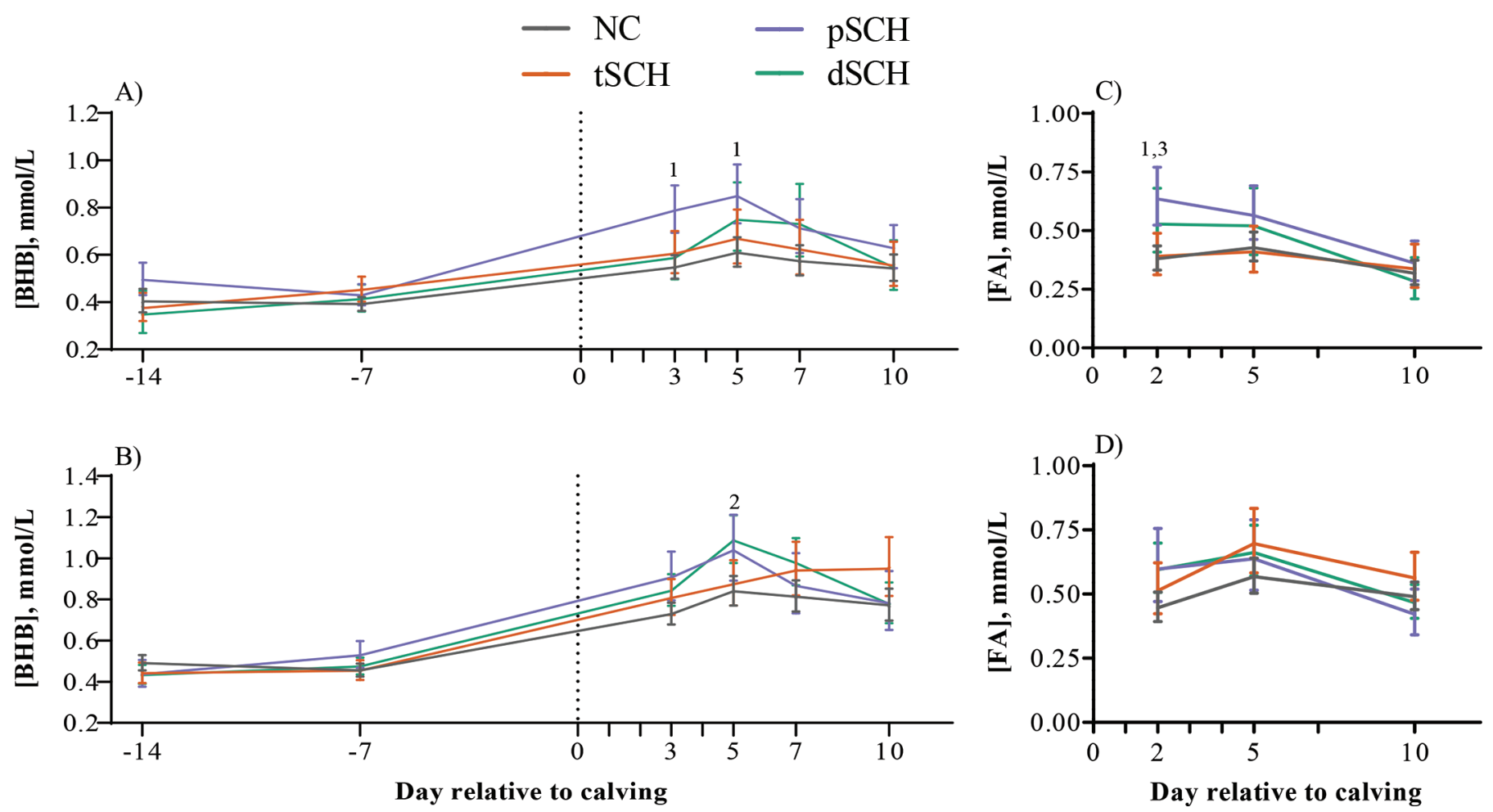

Figure 3. Least squares means and $95 \% \mathrm{CI}$ of blood BHB and plasma fatty acid (FA) concentrations in primiparous (A, C; $\mathrm{n}=144)$ and multiparous $(\mathrm{B}, \mathrm{D} ; \mathrm{n}=263)$ Holstein cows from 2 dairy herds in New York based on postpartum Ca status group. Cows were classified as follows: normocalcemic ( $\mathrm{NC}$, gray line; primiparous $[\mathrm{Ca}]>2.15 \mathrm{mmol} / \mathrm{L}$ at 1 and $2 \mathrm{DIM}$, multiparous $[\mathrm{Ca}]>1.77$ at $1 \mathrm{DIM}$ and $2.20 \mathrm{mmol} / \mathrm{L}$ at 4 DIM); transient subclinical hypocalcemia (tSCH, orange line; primiparous [Ca] $\leq 2.15$ at 1 DIM and $>2.15$ mmol/L at 2 DIM, multiparous [Ca] $\leq 1.77$ at 1 DIM and $>2.20 \mathrm{mmol} / \mathrm{L}$ at $4 \mathrm{DIM}$ ); persistent subclinical hypocalcemia (pSCH, purple line; primiparous [Ca] $<2.15 \mathrm{mmol} / \mathrm{L}$ at 1 and 2 DIM, multiparous $[\mathrm{Ca}] \leq 1.77$ at 1 DIM and $\leq 2.20 \mathrm{mmol} / \mathrm{L}$ at $4 \mathrm{DIM}$ ); or delayed subclinical hypocalcemia (dSCH, green line; primiparous $[\mathrm{Ca}]>2.15$ at 1 DIM and $\leq 2.15 \mathrm{mmol} / \mathrm{L}$ at $2 \mathrm{DIM}$, multiparous $[\mathrm{Ca}]>1.77$ at 1 DIM and $\leq 2.20 \mathrm{mmol} / \mathrm{L}$ at 4 DIM). Differences in BHB or FA concentrations among Ca status groups within a time point, based on a Bonferroni corrected $P<0.05$, are represented with numerals as follows: $1=\mathrm{NC}$ vs. pSCH, $2=\mathrm{NC}$ vs. dSCH, $3=\mathrm{tSCH}$ vs. pSCH.

DIM, and differing blood Ca concentrations at each DIM as in Neves et al. (2018b). Caixeta et al. (2017) reported a $20 \%$ prevalence of $\mathrm{NC}$, a $46 \%$ prevalence of $\mathrm{SCH}([\mathrm{Ca}] \leq 2.15 \mathrm{mmol} / \mathrm{L}$ at 1,2 , or $3 \mathrm{DIM})$, and a $34 \%$ prevalence of chronic SCH ([Ca] $\leq 2.15 \mathrm{mmol} / \mathrm{L}$ at 1,2 , and 3 DIM) in 97 cows from a single herd sampled repeatedly for the first 3 DIM. However, it is difficult to compare these studies as the case definition of SCH varied between them. Regardless, both studies, as discussed below, have found negative associations of hypocalcemia with the risk of adverse events when observing cows that are hypocalcemic beyond the traditionally accepted nadir of 24 to $48 \mathrm{~h}$ after parturition.

For primiparous cows, those with tSCH were no more likely than $\mathrm{NC}$ cows to have a disease or removal event (one or more of hyperketonemia, metritis, DA, or herd removal); however, in multiparous cows, those with $\mathrm{tSCH}$ tended to be at a higher risk for a disease or removal event than $\mathrm{NC}$ cows. The incidence of a disease or removal event in $\mathrm{NC}$ versus tSCH cows was 14.9 versus $20.0 \%$ in primiparous cows and 33.0 versus $50.0 \%$ in multiparous cows. Similarly, for both parity groups, cows with $\mathrm{pSCH}$ or $\mathrm{dSCH}$ had an increased risk of a disease or removal event over NC cows. Primiparous $\mathrm{dSCH}$ and pSCH cows were 3 and 4 times more likely, respectively, to experience a disease or removal event in the first 60 DIM than $\mathrm{NC}$ cows, with incidences of $47.4 \%$ for dSCH and $57.6 \%$ for pSCH cows. Although the relative risk was not as high for multiparous as primiparous cows, multiparous cows with $\mathrm{pSCH}$ and dSCH were almost twice as likely to experience a disease or removal event compared with $\mathrm{NC}$ cows, with incidences of 61.8 and $60.0 \%$, respectively. These findings are similar to those of Caixeta et al. (2017), where only $16 \%$ of normocalcemic cows developed any disease (retained placenta, clinical ketosis, metritis, or DA) in the first 10 DIM compared with $57 \%$ of cows with chronic $\mathrm{SCH}$. Also in agreement was a lack of difference 
in disease incidence when $\mathrm{SCH}$ cows, in a classification group somewhat similar to our tSCH status group, were compared with eucalcemic cows.

Numerous studies describe an association of SCH, albeit with different classification DIM and thresholds, with individual disease or removal events (Martinez et al., 2012; Rodríguez et al., 2017; Venjakob et al., 2018), and all show an increase in the risk of subsequent diseases or culling for cows with SCH. However, the method in which cows were classified as $\mathrm{SCH}$ often prevents separation of the data to identify differing groups that might better explain the true risk of hypocalcemia. For example, Rodríguez et al. (2017) collected blood at a single time point 24 to $48 \mathrm{~h}$ postpartum in 764 cows across 6 herds to diagnose SCH. Similarly, Venjakob et al. (2018) sampled 1,709 cows from 125 dairy herds in Germany and classified cows as SCH based on a single blood sample taken within $48 \mathrm{~h}$ after parturition. Although insightful for other reasons, these study designs do not provide an understanding of the direction of blood Ca concentration change in early lactation nor the time spent in a hypocalcemic state, and thus misclassification of tSCH cows as $\mathrm{SCH}$ and $\mathrm{dSCH}$ cows as $\mathrm{NC}$ in this scenario likely biases the association of $\mathrm{SCH}$ and disease toward the null hypothesis. Thus, the effect of $\mathrm{SCH}$, which our study suggests is due to cows with pSCH or dSCH, has likely been underestimated in recent studies. The findings of Martinez et al. (2012) might similarly underestimate the effect of $\mathrm{SCH}$ as cows were diagnosed if they had a serum Ca concentration $\leq 2.15 \mathrm{mmol} / \mathrm{L}$ at any one of the first 3 DIM; thus, tSCH cows, which are less likely to develop postpartum disease than $\mathrm{pSCH}$ or $\mathrm{dSCH}$ cows, would have been classified in the SCH category, thus reducing the estimated negative effect of SCH. Interestingly, although not stratified by parity group, the authors show that cows that developed metritis had lower serum Ca concentrations at all tested time points $(1,2,3,4,7$, and 12 DIM) compared with their herd mates that did not develop metritis. For cows that developed metritis, the average serum Ca concentration did not rise above $2.15 \mathrm{mmol} / \mathrm{L}$ until after 4 DIM, which is in agreement with our findings that disease or removal events are more likely to occur in cows with pSCH and $\mathrm{dSCH}$.

A large proportion of disease events that occurred in our study were due to hyperketonemia, which was defined as a blood BHB concentration $\geq 1.2 \mathrm{mmol} / \mathrm{L}$ at either $3,5,7$, or 10 DIM (Table 2). In primiparous cows, the incidence of hyperketonemia was numerically higher in $\mathrm{pSCH}$ and dSCH cows than $\mathrm{NC}$ or tSCH cows. In multiparous cows, tSCH, pSCH, and dSCH cows all had numerically higher incidences of hyperketonemia than NC cows. Our study was not designed, and thus underpowered, to find differences in blood
BHB concentration between specific Ca status groups at each DIM. However, in primiparous cows, differences in mean BHB concentrations between Ca status groups were noted at 3 and 5 DIM along with a difference in fatty acid concentrations at 2 DIM, with pSCH cows having the greatest concentrations of these metabolites at these DIM. It is possible that primiparous $\mathrm{pSCH}$ cows are in a greater state of energy deficit, although whether this is a contributor to or cause from hypocalcemia remains to be determined.

Similarly, multiparous pSCH and $\mathrm{dSCH}$ cows at 5 DIM had numerically greater blood BHB concentrations than $\mathrm{NC}$ or dSCH cows; interestingly, the slope of BHB concentration change in multiparous pSCH, dSCH, and NC cows declined after 5 DIM, whereas the slope in tSCH cows continued to increase. Thus, multiparous pSCH and dSCH cows contributed a numerically greater proportion of hyperketonemia cases at 3 and 5 DIM, whereas tSCH cows contributed a greater proportion of hyperketonemia cases at 7 and 10 DIM. This supports the notion that cows that develop hyperketonemia in the first week of lactation are more likely to have subsequent disease or removal events than cows that develop hyperketonemia in the second week of lactation (McArt et al., 2012; Tatone et al., 2016), perhaps due to different underlying mechanisms of hyperketonemia development. Caixeta et al. (2017) found a similar lack of statistical difference when comparing pre- and postpartum fatty acids and BHB between normocalcemic, $\mathrm{SCH}$, and chronic $\mathrm{SCH}$ cows, again likely due to a low sample size. However, when combined into a variable representing energy deficit, only $21 \%$ of normocalcemic cows were identified as having excessive energy deficit, whereas $76 \%$ of $\mathrm{SCH}$ and $85 \%$ of chronic $\mathrm{SCH}$ cows, respectively, were identified as such.

Given the difference in timing of hyperketonemia (HYK), and that the majority of disease or removal events in our study were due to HYK, it is possible that trend of increased disease or removal risk between tSCH and NC multiparous cows is due to HYK during the second week of lactation. Our study was underpowered to assess this idea completely. Further investigation is needed to determine if HYK at this time of lactation has the same negative associations with subsequent events or if it is merely a consequence of cows producing copious amounts of milk with limited feed intake. This is supported by our findings that cows with tSCH made more milk across the first 10 wk of lactation than NC cows. This large difference in milk yield, $3.4 \mathrm{~kg} / \mathrm{d}$ for primiparous cows and 4.5 $\mathrm{kg} / \mathrm{d}$ for multiparous cows, suggests that cows with tSCH are high milk producers that are adapting well to the increased $\mathrm{Ca}$ demand in early lactation, shown by their large drop in plasma $\mathrm{Ca}$ concentration at 1 
DIM and quick rebound by 2 or 4 DIM for primiparous and multiparous cows, respectively. Hypocalcemia, by definition, is required for secretion of parathyroid hormone and parathyroid hormone-related protein, which are essential for initiation of Ca homeostasis (Horst, 1986; Goff, 2014; Hernandez, 2017). High milk production leads to a quick drop in blood Ca concentration due to Ca secretion into colostrum and milk (Ramberg et al., 1984); the fact that cows can return to NC after hypocalcemia within a few days without treatment is evidence of an appropriate homeostatic response. It is likely that $\mathrm{tSCH}$ cows are metabolically unconstrained during their transition into lactation, resulting in a low incidence of disease and substantial milk yield.

Interestingly, milk yield across the first $10 \mathrm{wk}$ of lactation did not differ between multiparous tSCH and pSCH cows. Although tSCH cows made more milk in wk 1 than pSCH cows, pSCH cows eventually regained the average daily milk yield of $\mathrm{tSCH}$ cows as lactation progressed. As the plasma Ca concentration of $\mathrm{pSCH}$ cows drops at 1 DIM similar to tSCH cows, it is possible that these cows are similarly prepared for high milk production but have an intervening circumstance (e.g., injury, concurrent disease, treatment) that affects their ability to adapt appropriately in the first few days postpartum. This might delay their return to NC and increase their risk of early lactation disease or removal events. The adaptive ability of multiparous cows with $\mathrm{pSCH}$ to the initiation of lactation are likely different than those with dSCH, as multiparous dSCH cows have consistently, albeit numerically, lower milk production throughout the first $10 \mathrm{wk}$ of lactation. It is possible that dSCH multiparous cows are not similarly prepared for high milk production as pSCH cows and have an additional intervening circumstance that further constrains lactation. Given our study design and use of commercial dairy herds, we are unable to offer evidence on the association of DMI or the time sequence of disease or removal event occurrence with Ca status group, which are 2 topics that warrant further investigation.

It is difficult to provide supporting or refuting evidence for the above discussion as no other studies have evaluated the association of different types of $\mathrm{SCH}$ on disease and production outcomes; further investigation of these epidemiologic outcomes is warranted to improve external validity. Our results suggest that both primiparous and multiparous cows with tSCH are adapting well to the demands of early lactation. Primiparous cows with tSCH are no more likely to have a disease or removal event in early lactation than normocalcemic cows, and both primiparous and multiparous tSCH cows produced substantially more milk. Although it is plausible to hypothesize that these cows are producing a rigorous metabolic and hormonal response to changing mineral and energy requirements, this has yet to be proven. Similarly, we do not know what causes some cows to have persistent hypocalcemia when others rebound quickly, nor do we know why some cows are normocalcemic immediately after calving and then subsequently become hypocalcemic. These topics must be further explored to better understand the dynamics of calcium regulation and its effect on disease and production in early lactation cows.

\section{CONCLUSIONS}

Our study demonstrates that cows differ in the dynamics of plasma total Ca concentration change in the early postpartum period and that these differences are associated with the risk of disease or removal event diagnosis in the first 60 DIM and average daily milk yield over the first $10 \mathrm{wk}$ of lactation. Our results suggest that cows with tSCH have a smooth transition into lactation and make more milk than $\mathrm{NC}$ cows. Cows with pSCH or dSCH, regardless of parity group, are at an increased risk for early lactation disease or removal events, and thus represent cohorts of cows in which the early lactation change in total $\mathrm{Ca}$ concentrations indicate a suboptimal adaptation to lactation.

\section{ACKNOWLEDGMENTS}

This study was funded in part by Boehringer Ingelheim Animal Health USA Inc. (Duluth, GA), the President's Council of Cornell Women Affinito-Stewart Grant (Ithaca NY), and Elanco US Inc. (Greenfield, IN). The authors thank the participating herds and the efforts of Kathryn Bach, Anne Borkowski, Kaitlyn Briggs, Danielle Harris, Jamie Horstmann, Isabelle Louge, Morgan Robinson, Charlene Ryan, and Claira Seely (Cornell University, Ithaca, NY) during data collection. The authors declare no conflicts of interest. Jessica McArt was responsible for funding, study design, data analysis, and manuscript preparation; Rafael Neves was responsible for sample collection and processing, database compilation, and manuscript review.

\section{REFERENCES}

Bauman, D. E., and W. B. Currie. 1980. Partitioning of nutrients during pregnancy and lactation: A review of mechanisms involving homeostasis and homeorrhesis. J. Dairy Sci. 63:1514-1529. https:/ /doi.org/10.3168/jds.S0022-0302(80)83111-0.

Caixeta, L. S., P. A. Ospina, M. B. Capel, and D. V. Nydam. 2017. Association between subclinical hypocalcemia in the first 3 days of lactation and reproductive performance of dairy cows. Theriogenology 94:1-7. https://doi.org/10.1016/j.theriogenology.2017.01 .039 .

Drackley, J. K. 1999. ADSA Foundation Scholar Award. Biology of dairy cows during the transition period: The final frontier? 
J. Dairy Sci. 82:2259-2273. https://doi.org/10.3168/jds.S0022 -0302(99)75474-3.

Ferguson, J. D., D. T. Galligan, and N. Thomsen. 1994. Principal descriptors of body condition score in Holstein cows. J. Dairy Sci. 77:2695-2703. https://doi.org/10.3168/jds.S0022-0302(94)77212 $-\mathrm{X}$.

Goff, J. P. 2008. The monitoring, prevention, and treatment of milk fever and subclinical hypocalcemia in dairy cows. Vet. J. 176:50-57. https://doi.org/10.1016/j.tvjl.2007.12.020.

Goff, J. P. 2014. Calcium and magnesium disorders. Vet. Clin. North Am. Food Anim. Pract. 30:359-381. https://doi.org/10.1016/j .cvfa.2014.04.003.

Grummer, R. R. 1995. Impact of changes in organic nutrient metabolism on feeding the transition dairy cow. J. Anim. Sci. 73:28202833. https://doi.org/10.2527/1995.7392820x.

Hayirli, A., R. R. Grummer, E. V. Nordheim, and P. M. Crump. 2002. Animal and dietary factors affecting feed intake during the prefresh transition period in Holsteins. J. Dairy Sci. 85:3430-3443. https://doi.org/10.3168/jds.S0022-0302(02)74431-7.

Hernandez, L. L. 2017. TRIENNIAL LACTATION SYMPOSIUM/ BOLFA: Serotonin and the regulation of calcium transport in dairy cows. J. Anim. Sci. 95:5711-5719. https://doi.org/10.2527/ jas2017.1673.

Horst, R. L. 1986. Regulation of calcium and phosphorus homeostasis in the dairy cow. J. Dairy Sci. 69:604-616. https://doi.org/10 .3168/jds.S0022-0302(86)80445-3.

Martinez, N., C. A. Risco, F. S. Lima, R. S. Bisinotto, L. F. Greco, E. S. Ribeiro, F. Maunsell, K. Galvao, and J. E. Santos. 2012. Evaluation of peripartal calcium status, energetic profile, and neutrophil function in dairy cows at low or high risk of developing uterine disease. J. Dairy Sci. 95:7158-7172. https://doi.org/10.3168/jds $2012-5812$

McArt, J. A. A., D. V. Nydam, and G. R. Oetzel. 2012. Epidemiology of subclinical ketosis in early lactation dairy cattle. J. Dairy Sci. 95:5056-5066. https://doi.org/10.3168/jds.2012-5443.

Neves, R. C., B. M. Leno, K. D. Bach, and J. A. A. McArt. 2018b. Epidemiology of subclinical hypocalcemia in early-lactation Holstein dairy cows: The temporal associations of plasma calcium concentration in the first 4 days in milk with disease and milk production. J. Dairy Sci. 101:9321-9331. https://doi.org/10.3168/ jds.2018-14587.

Neves, R. C., B. M. Leno, M. D. Curler, M. J. Thomas, T. R. Overton, and J. A. A. McArt. 2018a. Association of immediate postpartum plasma calcium concentration with early-lactation clinical diseases, culling, reproduction, and milk production in Holstein cows. J. Dairy Sci. 101:547-555. https://doi.org/10.3168/jds.2017-13313.

Neves, R. C. B. M. Leno, T. Stokol, T. R. Overton, and J. A. A. McArt. 2017. Risk factors associated with postpartum subclinical hypocalcemia in dairy cows. J. Dairy Sci. 100:3796-3804. https:// doi.org/10.3168/jds.2016-11970.

NRC. 2001. Nutrient Requirements of Dairy Cattle. 7th rev. ed. Natl. Acad. Press, Washington, DC.

Oetzel, G. R. 2004. Monitoring and testing dairy herds for metabolic disease. Vet. Clin. North Am. Food Anim. Pract. 20:651-674 https://doi.org/10.1016/j.cvfa.2004.06.006.

Ospina, P. A., D. V. Nydam, and T. J. DiCiccio. 2012. Technical note: The risk ratio, an alternative to the odds ratio for estimating the association between multiple risk factors and a dichotomous outcome. J. Dairy Sci. 95:2576-2584. https://doi.org/10.3168/jds .2011-4515.

Ramberg, C. F. Jr., E. K. Johnson, R. D. Fargo, and D. S. Kronfeld. 1984. Calcium homeostasis in cows, with special reference to parturient hypocalcemia. Am. J. Physiol. 246:R698-R704. https://doi .org/10.1152/ajpregu.1984.246.5.R698.

Reinhardt, T. A., J. D. Lippolis, B. J. McCluskey, J. P. Goff, and R. L. Horst. 2011. Prevalence of subclinical hypocalcemia in dairy herds. Vet. J. 188:122-124. https://doi.org/10.1016/j.tvjl.2010.03.025.

Rodríguez, E. M. A. Aris, and A. Bach. 2017. Associations between subclinical hypocalcemia and postparturient diseases in dairy cows. J. Dairy Sci. 100:7427-7434. https://doi.org/10.3168/jds .2016-12210.

Sprecher, D. J., D. E. Hostetler, and J. B. Kaneene. 1997. A lameness scoring system that uses posture and gait to predict dairy cattle reproductive performance. Theriogenology 47:1179-1187. https:// doi.org/10.1016/s0093-691x(97)00098-8.

Tatone, E. H., T. F. Duffield, M. B. Capel, T. J. DeVries, S. J. LeBlanc, and J. L. Gordon. 2016. A randomized controlled trial of dexamethasone as an adjunctive therapy to propylene glycol for treatment of hyperketonemia in postpartum dairy cattle. J. Dairy Sci. 99:8991-9000. https://doi.org/10.3168/jds.2016-11358.

Venjakob, P. L., L. Pieper, W. Heuwieser, and S. Borchardt. 2018. Association of postpartum hypocalcemia with early-lactation milk yield, reproductive performance, and culling in dairy cows. J. Dairy Sci. 101:9396-9405. https://doi.org/10.3168/jds.2017-14202.

Vergara, C. F., D. Dopfer, N. B. Cook, K. V. Nordlund, J. A. McArt, D. V. Nydam, and G. R. Oetzel. 2014. Risk factors for postpartum problems in dairy cows: Explanatory and predictive modeling. J. Dairy Sci. 97:4127-4140. https://doi.org/10.3168/jds.2012-6440.

\section{ORCIDS}

J. A. A. McArt () https://orcid.org/0000-0001-5654-9172

R. C. Neves ๑ https://orcid.org/0000-0002-6595-3879 